\title{
Non-response to the recycling promotion technique of blockleader and commitment
}

\author{
Gonzalo Díaz Meneses* \\ Universidad de Las Palmas de Gran Canaria, Facultad de Ciencias Económicas y Empresariales, Módulo C, \\ despacho 1.15, 35017 Campus de Tafira, Las Palmas de Gran Canaria, The Canary Islands, Spain
}

\section{A R T I C L E I N F O}

\section{Article history:}

Received 29 November 2006

Received in revised form 14 July 2008

Accepted 28 August 2008

\section{JEL classification:}

M31

\section{Keywords:}

Social marketing

Recycling

Consumer behaviour

Blockleader promotion technique

\begin{abstract}
A B S T R A C T
The use of the recycling promotion technique which consists of commitment through a blockleader incentive has demonstrated that those individuals who are reluctant to increase their collaboration in response to the technique do not differ substantially from those who respond positively to the promotion, in terms of the processing information style. This similarity is clear, not only from the longitudinal perspective, which considers the evolution of these cognitive and evaluative variables from before the promotion application, but also from a transversal perspective, in other words, how the relationships between these variables are structured in both types of response model. However, the implications for management are based on the differences in the details of the two response patterns and a line of research based on the phenomenon of reluctance is justifiably proposed.
\end{abstract}

(C) 2008 Elsevier Inc. All rights reserved.

\section{Introduction}

Success in marketing a product lies in overcoming all possible resistance and, on many occasions the role of the marketing specialist is to develop tactics aimed at reducing reluctance to adopt (Hoyer and Macinnis, 2004). This has led Sheth (1981) to highlight the need for greater effort to be made in researching the phenomenon of non-adoption.

Similarly, in the field of recycling literature, in order to promote waste recycling collaboration behaviour, it is necessary to study the efficacy of recycling promotion techniques by analyzing the consumer response processes (Gamba and Oskamp, 1994; Dwyer et al., 1993; Wesley et al., 1995). In this context, the analysis of reluctance to recycle focuses on the objective of optimizing the management of selective waste collection campaigns which recognize the citizen as the provider of the raw materials to be recycled (Howenstine, 1993).

One of the most widely studied and used recycling promotion techniques to increase collaboration with recycling consists of commitment through the incentive of a blockleader. This technique entails the use of individuals from a single social network as the target public to convince their peers to develop a recycling conduct and so sign a symbolic written commitment to collaborate with recycling (McKenzie-Mohr, 1999). However, although this is one of the techniques with the highest response rates (Pardini and Katzev,

\footnotetext{
* Tel.: +34 928452807; fax: +34 928458117.

E-mail address: gdiaz@dede.ulpgc.es.
}

1983; Burns and Oskamp, 1986; Katzev and Pardini, 1987; Wang and Katzev, 1990; Bryce et al., 1997; Hopper and Nielsen, 1991), many works show that its response rate for an immediate increase in the recycling task is only $50 \%$. However, according to Porter et al. (1995), there has been no empirical study to explain the immediate effects of this technique on psychological information components since the approach has been merely theoretical.

On that basis, we prepared a quasi-experiment with the aim of explaining reluctance to increase collaboration with recycling after the application of the 'commitment at the incentive of a blockleader' technique. More specifically, the objectives of this research are: (1) to examine longitudinally the immediate effects on responders and non-responders to this technique, and (2) to represent transversely the model of response to the technique, comparing collaboration response with non-response. To that end, we have structured this work in four sections: (1) the review of the literature on the phenomenon of the diffusion of adoption behaviour and its application to recycling, followed by the proposal of hypotheses; (2) the methodological aspects, where details of the scales used are given and the experimental design is described; (3) the analysis of results to test the hypotheses, and (4) the conclusions, where the empirical evidence obtained and the theoretical implications are summarized and future lines of research are proposed.

\section{Review of the literature}

Reluctance is interpreted as being less threatening to marketing if it is conceived as a phase of the adoption process rather than as 
opposition to the concept of adoption itself (Ram, 1987). On that basis, reluctance to adopt the recycling conduct is seen as a natural, continuous reality in the process of introducing this desired behaviour into citizens. Therefore, the analysis of the causes of consumer reluctance should focus on the very factors that induce adoption since it is the modification of these factors that guides the consumer through the diffusion process.

In the area of ecology and recycling literature, the determinants of desired conduct adoption process can be classified into: (1) cognitive resources, which are ecological conscience (Arcury et al., 1986; Bigné, 1997) and beliefs abut recycling (Bagozzi and Dabholkar, 1994; Wesley et al., 1995) and (2) evaluative resources, such as ecological concern (Bohlen et al., 1993; Zimmer et al., 1994; Grunert and Jorn, 1995), recycling attitude (Oskamp et al., 1991) and involvement with recycling (McGuiness et al., 1977; Oskamp et al., 1991).

However, Hirschman (1987) states that the adoption process follows complex dynamics rather than regular and uniform dynamics, and recognizes that, on many occasions, although they have sufficient resources, consumers do not display higher levels of adoption simply because they do not consider it opportune. Therefore, Gatignon and Robertson (1989) distinguish two aspects in the non-adoption category: delay in taking action, and reluctance. In the latter case, consumers have decided not to collaborate, while in the former it is possible that they want more information or are waiting until they have better articulated attitudes to engage in the adoption process. In this respect, Venkatraman (1991) suggests that what is seen as apparent reluctance may constitute symbolic adoption, since the subject accepts the proposed ideas but postpones the purchase or increase in commitment. According to Mittelstaedt et al. (1976), reluctance does not necessarily imply an action of active rejection of the product, but a resistance to continue developing an adoption process that is increasingly less available, or in which the consumer receives detailed information, some aspects of which he/she does not agree with.

Moreover, various research works in recycling literature have shown that the recycling norm has become a routine or habit that is widely accepted within the citizen culture of advanced societies (Vining and Ebreo, 1990; Williams, 1991; Schlegelmilch et al., 1996; Diaz et al., 2004), with pro-environmental behaviour being the most widespread since there is no opposition to such an accepted ecological tradition (Ackerman, 1997). Therefore, on the basis of the theory about innovation diffusion proposed by Rogers (1995), it can be considered that we are in the final phase of belated adoption by a majority, or in the initial phase in the case of delayers or lagers, if they are not fully adopting but are informed and favourably disposed.

Consequently, on the basis that resistance to recycling is a temporary occurrence in the adoption process and not a concept opposed to recycling, in recognizing the level of maturity reached by citizens in terms of cognitive and evaluative resources, we propose the first two hypotheses:

H1. Responders and non-responders to the commitment at the incentive of a blockleader promotion technique display no substantial differences in their level of ecological conscience and concern, nor in their beliefs, attitude or recycling involvement either before or after the application of the technique.

H2. Responders and non-responders to the commitment at the incentive of a blockleader promotion technique display no substantial differences in the evolution of ecological conscience or concerns, nor in their beliefs, attitudes and recycling involvement after the application of the technique.
In the literature on recycling, Pardini and Katzev (1983) and Burns (1991) show that the success of the commitment technique depends on the individual feeling obliged to do what he/she promises, which represents an imperative of internal consistency. Similarly, Hopper and Nielsen (1991) and Bagozzi and Dabholkar (1994) state that one of the basic principles of the group-leader technique is that of social influence, which determines a certain coherence between beliefs, attitudes and the desired behaviour. On that empirical basis, Cacioppo and Petty's elaboration likelihood model (1984) could be considered a suitable theoretical framework to understand reluctance to respond to this promotion technique. It seems logical to consider that the central route of persuasion, that which generates stronger attitudes, is what characterizes the effects of the technique based on signing an undertaking at the incentive of a blockleader. This strength is described by the level of consistency between the components of beliefs and those of evaluation, as well as by the level of significant interrelations established in that structure of cognitions and evaluations (Chaiken and Stangor, 1987; Zanna et al., 1994; Petty and Krosnick, 1995). On the other hand, non-response is characterized, in general, by weaker, or less consistent, attitudes; in other words, by a more peripheral route and consequently by a lower level of significant interrelations in the variables of processing that are affected by the recycling promotion.

However, if the recycling norm is a generalized habit in terms of knowledge, attitudes and experience (Vining and Ebreo, 1990; Williams, 1991; Schlegelmilch et al., 1996; Ackerman, 1997; Diaz et al., 2004), there are probably no significant differences between the promotion response model and the non-response model. Furthermore, if we consider the non-adoption process to be a phase in the adoption process rather than a different model in itself (Ram, 1987), reluctance to increase recycling collaboration could not only be represented by the same type of model, with the same hierarchy of effect, but it should also not display any significant differences from the waste recycling collaboration response model. On this basis, we propose the following hypothesis:

H3. The model of reluctance to increase recycling after the application of the commitment with blockleader technique displays no significant differences from the model of response to that technique.

Drawing on the literature on innovation diffusion, it seems logical to assume that individuals are simply incapable of adopting what they do not perceive to be available (Hirschman, 1987). In this respect, the recycling literature clearly shows that the characteristics of the situation constitute the most significant inhibitor when the waste disposal guidelines are not followed (Hanson, 1980; Williams, 1991; Hornik et al., 1995; Dietz et al., 1998; Howenstine, 1993). More specifically, it is recognised that distance to the collection point, availability of time and space in the home, and the existence of mechanisms such as refund of deposits, rather than sanctions, are the most significant factors in terms of noncollaboration with recycling (Vining and Ebreo, 1990; Folz, 1991).

However, the consumer's perception of the recycling situation depends on his/her cognitive and evaluative resources since it is an essentially subjective perception (Shrum and Lowrey, 1995). In that respect, individuals with a greater knowledge of ecology and recycling (Young, 1988), and with more favourable attitudes and more involvement (Schuhwerk and Lefkokk-Hagius, 1995) are the ones who have the least difficulty in identifying with recycling.

We can therefore consider there to be practically no differences in the level and the evolution of the perceived convenience of recycling caused by the effect of the promotional application. This is because (1) there is an adequate level of development of the selective waste collection infrastructure, (2) the perception of the situation depends on the individuals' knowledge and attitudes, and 
(3) the recycling norms and the cognitive and evaluative resources of an ecological and recycling nature form a part of today's culture (Vining and Ebreo, 1990; Williams, 1991; Schlegelmilch et al., 1996; Ackerman, 1997). On that basis, we propose the following hypotheses:

H4. Responders and non-responders to the commitment with blockleader promotion technique display no substantial differences in the levels of their demands in their perceptions of the recycling situation either before or after the application of that technique.

H5. Responders and non-responders to the commitment with blockleader promotion technique display no substantial differences in the evolution of the perceptions of the recycling situation after the application of the technique.

\section{Methodological aspects}

With the aim of empirically analyzing non-response to the promotion technique of signing an undertaking at the incentive of a blockleader, we have developed a quasi-experimental design, which is characterized by its natural contexts with conveniently formed groups (Moreno and López, 1985). This technique was considered the independent variable while ecological conscience, recycling beliefs, ecological concern, involvement with recycling, and attitude toward recycling were regarded as the dependent variables.

The designed treatment consisted of applying the technique of an individual signing an undertaking at the incentive of a blockleader. The written commitment was as follows: "I, name of subject, wish to recycle glass, paper or carton and tetrabrick containers, and accept this commitment in order to support the recycling work in my local authority area". The blockleaders comprised a team of 123 volunteers recruited among students at our education centre. Each of these blockleaders or students chose a member of his/her
Table 1

The sample frequencies

\begin{tabular}{ll}
\hline & Percent \\
\hline Gender & \\
Male & 40.7 \\
Female & 59.3 \\
Age & \\
$18-23$ & 15.9 \\
$24-30$ & 17.9 \\
$31-45$ & 18.7 \\
$46-60$ & 37.0 \\
$>60$ & 10.6 \\
Level of education & \\
Without & \\
Primary & 7.3 \\
Secondary & 34.1 \\
Colleges & 35.8 \\
University & 12.2 \\
& 10.6
\end{tabular}

household to form part of the research sample (see Table 1). Each volunteer was responsible for applying the promotion technique by assuming the role of blockleader to the selected member of the household. This role consisted of providing a letter with a statement of commitment and establishing an informative discussion whose script contained the following aspects: (1) the principal ecological problems and possible solutions; (2) the where, how and why for of recycling; (3) the threat of environmental deterioration and its main dangers; (4) the desirability and positive nature of recycling; and (5) the importance and relevance of the recycling task in the household of the selected individual.

Table 2 shows the chronogram of the experiment, which lasted 3 weeks, although the actual promotion lasted little more than a week, during which time the informative discussion had to last no more than $45 \mathrm{~min}$ over a maximum of three sessions. Once all

Table 2

Program of activities

\begin{tabular}{|c|c|c|c|c|c|c|c|c|c|c|c|c|c|c|c|c|c|c|c|c|c|c|c|c|c|c|c|c|c|c|c|}
\hline & \multicolumn{31}{|c|}{ OCTOBER 2002} \\
\hline & $\mathrm{T}$ & W & Th & $F$ & S & S & M & $\mathrm{T}$ & W & Th & $\mathrm{F}$ & $S$ & $S$ & M & $\mathrm{T}$ & W & Th & $\mathrm{F}$ & $S$ & $S$ & M & $\mathrm{T}$ & W & Th & $\mathrm{F}$ & $S$ & $S$ & $M$ & $\mathrm{~T}$ & W & Th \\
\hline & 1 & 2 & 3 & 4 & 5 & 6 & 7 & 8 & 9 & 10 & 11 & 12 & 13 & 14 & 15 & 16 & 17 & 18 & 19 & 20 & 21 & 22 & 23 & 24 & 25 & 26 & 27 & 28 & 29 & 30 & 31 \\
\hline P1 & & & & & & & & & & & & & & & & & & & & & & & & & & & & & & & \\
\hline P2 & & & & & & & & & & & & & & & & & & & & & & & & & & & & & & & \\
\hline P3 & & & & & & & & & & & & & & & & & & & & & & & & & & & & & & & \\
\hline PR & & & & & & & & & & & & & & & & & & & & & & & & & & & & & & & \\
\hline B & & & & & & & & & & & & & & & & & & & & & & & & & & & & & & & \\
\hline D & & & & & & & & & & & & & & & & & & & & & & & & & & & & & & & \\
\hline & & VE & MBE & $R$ & 00 & & & & & & & & & & & & & & & & & & & & & & & & & & \\
\hline & V & S & D & L & M & $x$ & $\mathrm{~J}$ & V & $S$ & D & L & M & $x$ & $J$ & V & $S$ & D & L & M & $x$ & $\mathrm{~J}$ & V & $S$ & D & L & $M$ & $x$ & $J$ & V & S & $D$ \\
\hline & 1 & 2 & 3 & 4 & 5 & 6 & 7 & 8 & 9 & 10 & 11 & 12 & 13 & 14 & 15 & 16 & 17 & 18 & 19 & 20 & 21 & 22 & 23 & 24 & 25 & 26 & 27 & 28 & 29 & 30 & 31 \\
\hline P1 & & & & & & & & & & & & & & & & & & & & & & & & & & & & & & & \\
\hline P2 & & & & & & & & & & & & & & & & & & & & & & & & & & & & & & & \\
\hline P3 & & & & & & & & & & & & & & & & & & & & & & & & & & & & & & & \\
\hline PR & & & & & & & & & & & & & & & & & & & & & & & & & & & & & & & \\
\hline B & & & & & & & & & & & & & & & & & & & & & & & & & & & & & & & \\
\hline D & & & & & & & & & & & & & & & & & & & & & & & & & & & & & & & \\
\hline
\end{tabular}

P1: Duration of the first phase of the questionnaire and submission to the research directors. P2: Duration of the second phase of the questionnaire and submission to the research directors. PR: Duration of promotions. B: Data base processing. D: Direct measurement of recycling conduct. 
Table 3

Factor analyses on the variables of situation

\begin{tabular}{|c|c|c|c|c|c|c|}
\hline \multirow[t]{3}{*}{ Dimensions } & \multicolumn{6}{|c|}{ Factors } \\
\hline & \multicolumn{3}{|c|}{ Step 1} & \multicolumn{3}{|c|}{ Step 2} \\
\hline & F1 & $\mathrm{F} 2$ & F3 & F1 & $\mathrm{F} 2$ & F3 \\
\hline $\begin{array}{l}\text { If the recycling container were nearer } \\
\text { my house }\end{array}$ & 0.15 & 0.04 & 0.89 & 0.12 & 0.08 & 0.87 \\
\hline $\begin{array}{l}\text { If I was informed about the location of } \\
\text { the containers }\end{array}$ & 0.06 & 0.14 & 0.89 & 0.02 & 0.24 & 0.85 \\
\hline If I had a bigger house & 0.01 & 0.80 & 0.11 & 0.05 & 0.79 & 0.18 \\
\hline If I had more time & 0.05 & 0.69 & 0.07 & 0.20 & $\mathbf{0 . 7 0}$ & 0.16 \\
\hline If there were a possible fine or penalty & 0.76 & 0.23 & 0.04 & 0.84 & 0.13 & 0.02 \\
\hline If I was paid something for the effort & 0.79 & 0.08 & 0.03 & 0.76 & 0.22 & 0.07 \\
\hline $\begin{array}{l}\text { If the recycling waste did not smell so } \\
\text { bad }\end{array}$ & 0.30 & 0.75 & 0.05 & 0.29 & $\mathbf{0 . 7 9}$ & 0.04 \\
\hline $\begin{array}{l}\text { If the recycling waste were not so } \\
\text { unsightly in the house }\end{array}$ & 0.24 & 0.78 & 0.02 & 0.26 & 0.80 & 0.09 \\
\hline If I had to obey a law & 0.78 & 0.07 & 0.04 & 0.78 & 0.14 & 0.18 \\
\hline \multirow[t]{2}{*}{ If there were some tax relief } & 0.76 & 0.14 & 0.03 & 0.77 & 0.27 & 0.14 \\
\hline & \multicolumn{3}{|c|}{ V. ex. 66.353\%, KMO: 0.709, Bartlett: 861.284, Sig. 0.000} & \multicolumn{3}{|c|}{ V. ex. $70.188 \%$, KMO: 0.786, Bartlett: 1101.399 , Sig. 0.000} \\
\hline
\end{tabular}

the necessary information had been gathered by means of questionnaires, it was introduced into a data base after some cases had been eliminated either because an internal incoherence was detected, the research objective had been discovered by the experimental subject or the subject had ceased to collaborate during the experiment period. After discarding 15 cases, the real sample consisted of 123 individuals. Furthermore, since all the sample elements belonged to our students' households, the sample selection process was of a convenient nature, although with allocation proportional to the characteristics of age and sex of the universe. In this case, the design of our sample of convenience appeared to be adequate, since we were concerned with increasing the opportunity for observation and control of the selected subjects.

As mentioned above, the method used to gather information about cognitive and evaluative aspects of an ecological and recycling nature, as well as about recycling conduct, was a questionnaire featuring questions on the following variables of the study:

- Ecological conscience: a 4-item, 5-point Likert type scale based on that proposed by Bohlen et al. (1993) and referring to information about knowledge of ecological damage and the impact of one's own actions on nature.

- Beliefs about recycling: a 6-item, 5-point Likert type scale based on Scholder (1994) and referring to practical information about the function of recycling.

- Involvement with recycling: a 4-item, 5-point semantic differential question based on Zaichkowsky (1985) and Diaz and Beerli (2002) and defined as involvement and responsibility regarding recycling.

- Attitude toward recycling: a 4-item, 5-point semantic differential question based on Biswas et al. (2000), which is described as a favourable or unfavourable evaluation of recycling.

- Ecological concern: a 4-item, 5-point Likert type scale based on Dunlap and Van Liere (1984) and Grendstad (1999), to gather information about the respondent's disquiet about the balance of nature and the possibility of an ecological crisis.

- Recycling conduct: three Likert type questions, each with one item and five points, referring to the respondent's level of collaboration related to the total glass, paper and container material generated in the household and to be recycled. With regard to this variable it should be made clear that the information contained on the questionnaires was compared with the opinion of the relevant student collaborator in order to detect any significant discrepancies regarding the true behaviour of the experimental subjects.
- Perceived situation: a question with a 10-item, 5-point Likert type scale based on Everett and Peirce (1992) referring to which factors of the situation should improve for the respondent's recycling effort to increase substantially.

\section{Analysis of results}

\subsection{Preliminary results}

Prior to testing the proposed hypotheses, we conducted exploratory factor analyses, Cronbach's alpha and confirmatory factor analyses in order to check the validity and reliability of the measuring instruments related to the cognitive and evaluative components of an ecological and recycling nature. The exploratory factor analysis with varimax rotation of principal components identified all the ecological and recycling characteristics under consideration, and explained variances of above $60 \%$ except in the case of ecological concern with explained variances of around $50 \%$. Similarly, all the scales display convergent validity although the scale for ecological concern obtains standardized estimators that are significant and positive but below the critical threshold of 0.5 . Furthermore, the compound reliability and Cronbach's alpha analyses gave values above the recommended level except in the case of the extracted variance of ecological concern, which is slightly below 0.5 . Lastly, the correlations analysis shows that ecological concern, recycling beliefs, attitude to recycling and involvement with recycling measure different ecological and recycling realities since Pearson's correlation coefficient differs significantly from 1 (Diaz et al., 2004). In addition, an exploratory factor analysis of the scale for perceived situation was applied and the Cronbach's alpha examined to show the internal consistency of the scale (see Tables 3 and 4).

Before the hypothesis tests, two sub-samples were created comprising the following: (1) individuals whose recycling conduct remained the same, or diminished, after the promotion was implemented, and (2) individuals whose collaboration with the recycling of waste increased immediately after the promotion.

Table 4

Cronbach's alpha reliability analysis of the characteristics of situation

\begin{tabular}{llll}
\hline Types of variable & Dimensions & Step 1 & Step 2 \\
\hline Situation & Legal-financial & 0.80 & 0.83 \\
& Personal domestic inconveniences & 0.78 & 0.83 \\
& Public facilitators & 0.76 & 0.73 \\
\hline
\end{tabular}


Table 5

$T$-test for the independent samples of responders and non-responders for the examination of the variables of processing before and after the promotion

\begin{tabular}{lllllll}
\hline & $N$ & Conscience & Beliefs & Concern & Attitude & Involvement \\
\hline T1 & & & & & & \\
$\quad$ No increase & 52 & 3.0451 & 2.4676 & 2.4753 & 3.3378 & 3.2835 \\
Increase & 71 & 2.9095 & 2.2660 & 2.4385 & 2.8231 & 3.0087 \\
$\quad$ Significance & & 0.277 & 0.034 & 0.625 & 0.005 & 0.071 \\
T2 & & & & & & \\
$\quad$ No increase & 52 & 2.7584 & 2.6424 & 2.2643 & 3.1957 & 3.2381 \\
Increase & 71 & 2.7589 & 2.7496 & 2.2294 & 3.3425 & 3.4341 \\
Significance & & 0.996 & 0.244 & 0.608 & 0.291 & 0.109 \\
\hline
\end{tabular}

After doing it, the first comment on the results obtained should highlight the evidence that the variables defined not only as ecological concern and conscience, but also as beliefs, attitude and involvement with recycling are mid-scale score, much lower than the maximum of 5. Furthermore, the means differences test to compare the responders and non-responders to the blockleader with commitment technique shows that responders and nonresponders do not diverge at any level of ecological and recycling aspects (Table 5). This contradicts the predominant understanding about recycling in environmental literature since recycling is not motivated by a very high commitment with a robust ecological ideology. Thus, as mentioned in the literature review, recycling appears be a solid part of our contemporary culture, i.e. a routine without any radical connotations (Vining and Ebreo, 1990). Moreover, this evidence points out the opportunity of reducing cost, given that it is easier to reinforce an attitude or value than change it.

\subsection{Analyses to test Hypotheses 1 and 2}

Using these sub-samples, and in order to examine whether reluctance to respond to the commitment with blockleader technique displays a similar level of cognitive and evaluative, ecological and recycling resources as the incremental response to that technique, two analyses of mean differences consisting of two $T$-tests for independent samples were conducted, one before and one after the promotion application. Table 5 shows the results obtained, which reveal that those reluctant to respond are characterized by having greater knowledge of the how and why of recycling, as well as a
Table 6

$T$-test for intra-subject related samples for responders and non-responders to identify the immediate effects on the promotion processing variables

\begin{tabular}{lllllll}
\hline & $N$ & Conscience & Beliefs & Concern & Attitude & Involvement \\
\hline T1 & & & & & & \\
$\quad$ No increase & 52 & 3.0451 & 2.4676 & 2.4753 & 3.3378 & 3.2835 \\
$\quad$ Increase & 71 & 2.9095 & 2.2660 & 2.4385 & 2.8231 & 3.0087 \\
T2 & & & & & & \\
$\quad$ No increase & 52 & 2.7584 & 2.6424 & 2.2643 & 3.1957 & 3.2381 \\
$\quad$ Increase & 71 & 2.7589 & 2.7496 & 2.2294 & 3.3425 & 3.4341 \\
$\quad$ T1-T2 & & & & & & \\
$\quad$ Sig. No increase & & 0.001 & 0.002 & 0.000 & 0.026 & 0.482 \\
$\quad$ Sig. Increase & & 0.086 & 0.000 & 0.000 & 0.000 & 0.000 \\
\hline
\end{tabular}

better attitude and higher involvement than those who respond. However, both non-responders and responders to the promotion display the same levels of ecological conscience and concern. Moreover, once the promotion is applied, the sub-samples display no significant differences in the levels of cognitive and evaluative, ecological and recycling resources.

On that basis, Hypothesis 1 is accepted since responders and non-responders to the commitment at the incentive of a blockleader promotion technique do not differ significantly in their levels of ecological conscience and concern, recycling attitude and involvement, after the application of the technique. However, before the application there were statistically significant differences between the recycling resources of responders and those of non-responders, since the non-responders' beliefs, attitudes and involvement with recycling were greater than those of the responders, at least before the promotion was applied.

Two $T$-tests for related samples were conducted to show that the variables of the ecological and recycling cognitive and evaluation process of those reluctant to increase their level of recycling collaboration after the promotion do not display any significant variation from those who respond to the technique.

The results in Table 6 clearly show that non-responders to the promotion are characterized by a reduction in their ecological conscience and concern and in their attitude toward recycling. However, there is no statistically significant variation in their involvement with recycling and they even increase their knowledge about the how and why of recycling. The main difference

Table 7

MLG of repeated measures of variables of processing to identify the immediate inter-subject differential effects of responders and non-responders to the promotion

\begin{tabular}{|c|c|c|c|c|c|}
\hline Effect & Sum of type III squares & Gl & Quadratic mean & $F$ & Significance \\
\hline \multicolumn{6}{|c|}{ Ecological conscience } \\
\hline Evolution & 1975.134 & 1 & 1975.134 & 4132.304 & 0.000 \\
\hline Interaction & 0.274 & 1 & 0.274 & 0.573 & 0.450 \\
\hline Error & 57.835 & 121 & 0.478 & & \\
\hline \multicolumn{6}{|c|}{ Recycling beliefs } \\
\hline Evolution & 1538.743 & 1 & 1538.743 & 3806.911 & 0.000 \\
\hline Interaction & 0.133 & 1 & 0.133 & 0.330 & 0.567 \\
\hline Error & 48.908 & 121 & 0.404 & & \\
\hline \multicolumn{6}{|c|}{ Ecological concern } \\
\hline Evolution & 1328.228 & 1 & 1328.228 & 5684.121 & 0.000 \\
\hline Interaction & 0.077 & 1 & 0.077 & 0.331 & 0.566 \\
\hline Error & 28.274 & 121 & 0.234 & & \\
\hline \multicolumn{6}{|c|}{ Attitude toward recycling } \\
\hline Evolution & 2420.324 & 1 & 2420.324 & 1801.284 & 0.000 \\
\hline Interaction & 2.033 & 1 & 2.033 & 1.513 & 0.221 \\
\hline Error & 162.584 & 121 & 1.344 & & \\
\hline \multicolumn{6}{|c|}{ Involvement with recycling } \\
\hline Evolution & 2522.518 & 1 & 2522.518 & 2605.659 & 0.000 \\
\hline Interaction & 0.093 & 1 & 0.093 & 0.096 & 0.757 \\
\hline Error & 117.139 & 121 & 0.968 & & \\
\hline
\end{tabular}


between non-responders and responders to the promotion is found in the formers' recycling attitude and involvement, which increase substantially, and in their ecological conscience, which displays no statistically significant variation.

However, an analysis based on the General Linear Model for repeated measures was applied to compare the ecological and recycling cognitive and evaluative process of responders and nonresponders. The results of that analysis showed that there are no statistically significant differences between the evolution of these variables in the case of responders and in the case of nonresponders (see Table 7 ).

Based on the above, Hypothesis 2, which proposes that responders and non-responders to the commitment at the incentive of a blockleader promotion technique do not substantially differ in the evolution of their ecological conscience and concern, or in terms of their beliefs, attitude and involvement with recycling after the application of the technique, is accepted.

The results obtained related to both hypotheses point to a significant reduction of the marginal utility to be obtained by the blockleader and commitment promotion, such as explained by the law of decreasing performance. In other words, it seems clear that the implementation of this promotional technique does not exert great impact in term of recycling offer expansion. Therefore recycling behaviour obtained after implementing this technique is costly and therefore only makes sense if the public policy maker wants to achieve the recycling conversion of the entire favourable market, as is the case with very polluting residuals such as batteries.

\subsection{Analyses to test Hypothesis 3}

Two stages were followed to examine any statistically significant differences between the response to the promotion technique model and the non-response model; firstly, the theoretical stage, in which the variables to be included in the model are set out, and secondly, the empirical stage, aimed at selecting a model that represents the norms of response and non-response to the promotion. To that end, and in line with Gerbing and Anderson (1988) and Hair et al. (1999) several alternative models were estimated in order to make comparisons that would lead to the choice of an optimum model that would constitute the definitive model to represent the norms of response to the recycling promotion technique. In order to simplify this task and since the systems for collection of glass, paper and cardboard, and tetrabrick cartons have similar levels of development, they were combined and the recycling behaviour variable was established by means of an arithmetical average. The final model was selected after examining the significance of the Chisquared statistic and the indicators that the literature considered especially useful in the comparison of models.

After the selection of the final model, the latter was estimated on the sub-sample of the individuals reluctant to respond to the commitment at the incentive of a blockleader technique. Then a Chi-squared differences test for multi-groups was run between the models with and without restrictions of equality in the regression weights of the parameters of the relationship between the two sub-samples. On that basis, and as Table 8 and Fig. 1 show, both models show a good fit to the data and there are no statistically significant differences at an overall level between the processes of non-response and response to the promotion technique.

However, the Chi-squared differences tests for each parameter of relationship between the variables of the response model and the non-response model indicate that there are statistically significant differences at the relationship parameter level. In fact, the critical ratios and the standardized estimators of both models reveal that the response to the promotion process displays a significantly more interdependent structuring of variables than the non-response process. To be more specific, (1) the responders'

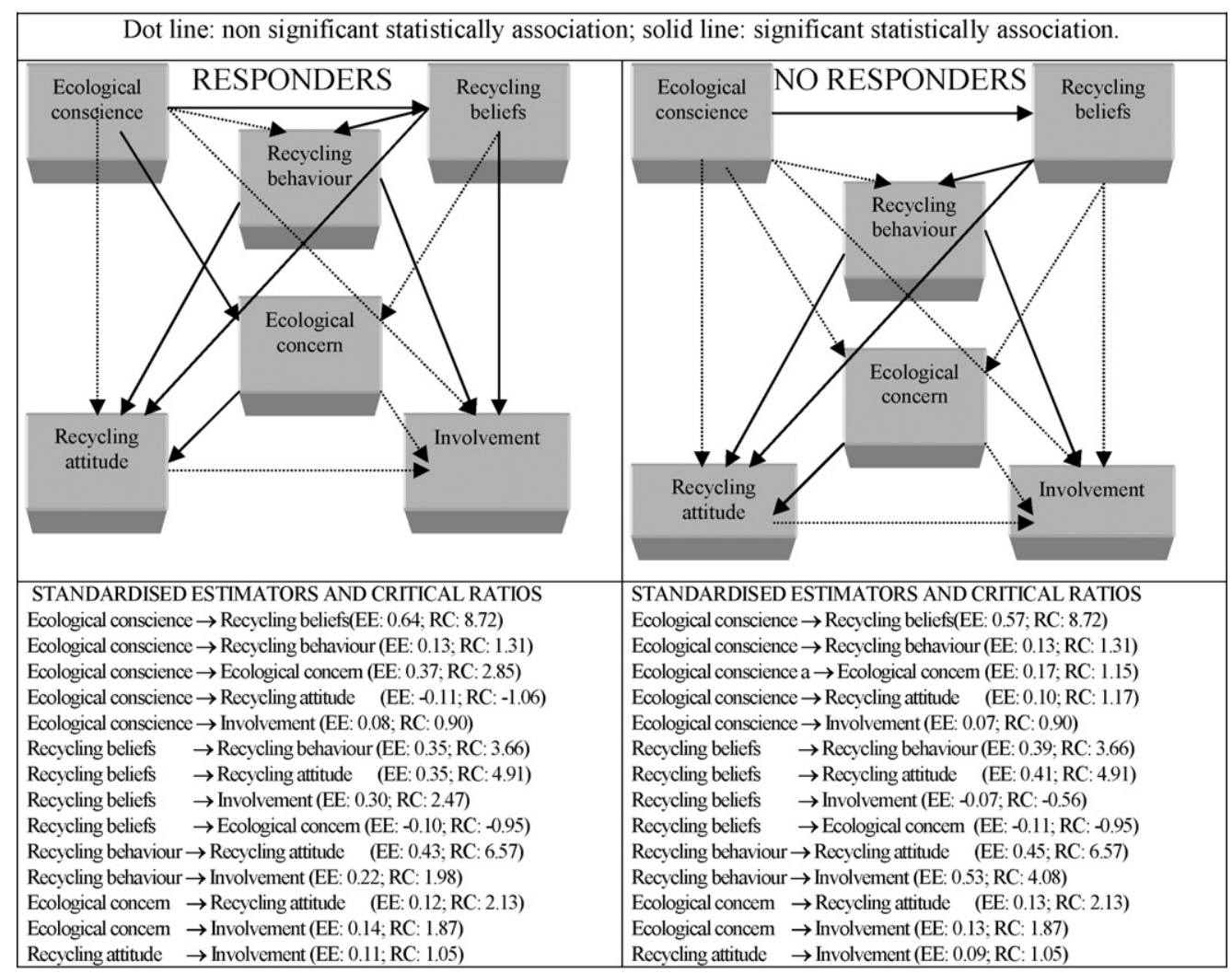

Fig. 1. Chi-square multi-group type test of differences: sub-samples of responders and non-responders to the blockleader technique at T2. 
Table 8

Chi-square multi-group type test of differences: sub-samples of responders and nonresponders to the blockleader technique at $\mathrm{t} 2$

\begin{tabular}{lrrr}
\hline Equality restrictions of the regression weights & \multicolumn{2}{l}{ Blockleader } & \\
\cline { 2 - 4 } $\begin{array}{l}\text { in the sub-samples of responders and } \\
\text { non-responders }\end{array}$ & CMIN & GL & P \\
\hline Ecological conscience $\rightarrow$ Recycling beliefs & 0.68 & 1 & 0.69 \\
Ecological conscience $\rightarrow$ Recycling behaviour & 0.01 & 1 & 0.91 \\
Ecological conscience $\rightarrow$ Ecological concern & 3.40 & 1 & 0.06 \\
Ecological conscience $\rightarrow$ Recycling attitude & 4.42 & 1 & 0.03 \\
Ecological conscience $\rightarrow$ Recycling involvement & 0.36 & 1 & 0.80 \\
Recycling beliefs $\rightarrow$ Recycling behaviour & 0.27 & 1 & 0.82 \\
Recycling beliefs $\rightarrow$ Recycling attitude & 0.98 & 1 & 0.61 \\
Recycling beliefs $\rightarrow$ Recycling involvement & 4.42 & 1 & 0.03 \\
Recycling beliefs $\rightarrow$ Ecological concern & 2.57 & 1 & 0.14 \\
Recycling behaviour $\rightarrow$ Recycling attitude & 0.27 & 1 & 0.82 \\
Recycling behaviour $\rightarrow$ Recycling involvement & 3.00 & 1 & 0.08 \\
Ecological concern $\rightarrow$ Recycling attitude & 2.65 & 1 & 0.11 \\
Ecological concern $\rightarrow$ Recycling involvement & 0.25 & 1 & 0.83 \\
Recycling attitude $\rightarrow$ Recycling involvement & 0.00 & 1 & 0.94 \\
Equality between all the regression weights & 18.57 & 14 & 0.12 \\
Equality between the regression weights, & 7.40 & 10 & 0.81 \\
except in significant parameters & & & \\
\hline
\end{tabular}

Table 9

$T$-test for the independent samples of responders and non-responders to examine the variables of perceived situation before and after the promotion

\begin{tabular}{lllll}
\hline & $N$ & Domestic & Public & Reinforcements \\
\hline T1 & & & & \\
$\quad$ Do not increase & 52 & 3.29 & 2.87 & 3.25 \\
$\quad \begin{array}{l}\text { Increase } \\
\text { Significance }\end{array}$ & 71 & 2.87 & 3.30 & 3.14 \\
T2 & & 0.108 & 0.077 & 0.665 \\
$\quad$ Do not increase & 52 & 3.27 & & \\
$\quad$ Increase & 71 & 2.99 & 3.06 & 3.06 \\
$\quad$ Significance & & 0.276 & 0.400 & 0.952 \\
\hline
\end{tabular}

recycling involvement is a direct consequence not only of the recycling experience or behaviour, as in the case of non-responders, but also of their knowledge of the how and why of recycling, or beliefs about recycling, and (2) the responders' attitude toward recycling is due not only to a feeling of disquiet about the environment, as in the case of non-responders, but their ecological concern is a result of their ecological conscience.

Consequently, on the basis that while there are no significant differences at a model level, such differences do exist at a level of determined parameters of relationship between variables, and it can thus be concluded that the model of reluctance to increase recycling behaviour as the effect of the commitment with block-
Table 10

$T$-test for the independent samples of responders and non-responders to identify the immediate effects of the promotion on the variables of perceived situation of recycling

\begin{tabular}{lllll}
\hline & $N$ & Domestic & Public & Reinforcement \\
\hline T1 & 52 & 3.29 & 2.87 & 3.25 \\
$\quad$ Do not increase & 71 & 2.87 & 3.30 & 3.14 \\
$\quad$ Increase & & & & \\
T2 & 52 & 3.27 & 3.06 & 3.06 \\
$\quad$ Do not increase & 71 & 2.99 & 3.27 & 3.04 \\
$\quad$ Increase & & & & \\
T1-T2 & & 0.928 & 0.366 & 0.249 \\
$\quad$ Significance. No increase & & 0.515 & 0.886 & 0.446 \\
$\quad$ Significance. Increase & & & & \\
\hline
\end{tabular}

leader technique displays no significant differences from the model of response to that technique. Therefore, Hypothesis 3 is accepted. This is so since recycling is something widespread as well as accepted in society and close is the day when we shall have to deal with laggards, although it is known that this only occurs at a very advanced phase of diffusion. In this case and thus dealing with lower motivated people, external stimuli are the most suitable measure to promote recycling and then economic variables, such as incentives, will explain any increase, since the key to promotional success is not only related to providing information. Therefore, it seems logical to suggest that public policy makers implement different policies to promote recycling by putting more emphasis on external economical incentives, for instances, taxes and subsidies, in order to make a difference in term of the recycling material quantities provided by citizens.

\subsection{Analyses to test Hypotheses 4 and 5}

In order to show that there are no differences in the levels of convenience that rejecters and followers of the promotion perceive in the selective waste collection system, an analysis was carried out comprising two $T$-tests, one for responders and another for non-responders to the commitment with blockleader technique. Table 9 shows that the perceived availability of time and space in the household, distance to the recycling containers, and the presence of reinforcement mechanisms such as fines or prizes does not distinguish responders from non-responders. However, the perceived distance of the selective waste collection points is close to the critical threshold of statistical significance since those who increase their collaboration as a result of the promotion require the containers to be nearer to the household. Based on the above, Hypothesis 4 is accepted since responders and non-responders to the promotion

Table 11

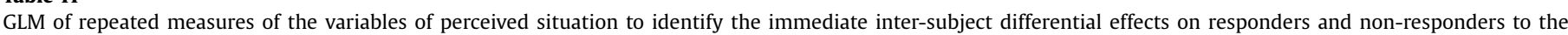
promotion

\begin{tabular}{|c|c|c|c|c|c|}
\hline Effect & Sum of type III squares & Gl & Quadratic average & $F$ & Significance \\
\hline \multicolumn{6}{|l|}{ Domestic } \\
\hline Evolution & 2313.925 & 1 & 2313.925 & 802.918 & 0.000 \\
\hline Interaction & 7.323 & 1 & 7.323 & 2.541 & 0.114 \\
\hline Error & 348.709 & 121 & 2.882 & & \\
\hline \multicolumn{6}{|l|}{ Public } \\
\hline Evolution & 2339.942 & 1 & 2339.942 & 1009.104 & 0.000 \\
\hline Interaction & 6.153 & 1 & 6.153 & 2.654 & 0.106 \\
\hline Error & 280.579 & 121 & 2.319 & & \\
\hline \multicolumn{6}{|l|}{ Reinforcement } \\
\hline Evolution & 2341.566 & 1 & 2341.566 & 732.405 & 0.000 \\
\hline Interaction & 0.233 & 1 & 0.233 & 0.073 & 0.788 \\
\hline Error & 386.848 & 121 & 3.197 & & \\
\hline
\end{tabular}


technique of commitment at the incentive of a blockleader do not differ substantially in the level of their requirements regarding their perceptions of the recycling situation before and after the application of the promotion technique.

Finally, a $T$-test for related samples was conducted in order to examine the sign and significance of the changes in the situation perceived by those subjected to the promotion. We also carried out an analysis based on the General Linear Model for repeated measures in order to evaluate the existence of differences in the evolution of convenience, depending on response or non-response to the recycling promotion technique. As Tables 10 and 11 show, there are no statistically significant changes in any of the dimensions of the perceived situation as a result of the application of the promotion, not only among those who increase their collaboration but also among those who do not respond, or even reduce their collaboration. Therefore, responders and non-responders to the promotion technique of commitment at the incentive of a blockleader display no substantial differences in the evolution of the perceived recycling situation after the application of the promotion and Hypothesis 5 is accepted.

Hypotheses 4 and 5 suggest the intervention on situational variables would not be costly deserved at an advanced phase of diffusion, given that the expected benefit to be obtained by further developing the collecting infrastructure does not make any difference in term of the amount of recycling. Therefore, the cost of operating on situational variables exceeds the benefits resulting from the subsequent increase in reinforcing the recycling behaviour model.

\section{Conclusions}

The results of this research show that the consumers' norms for recycling have become a consolidated habit, and they therefore also demonstrate the efficacy of the commitment at the incentive of a blockleader technique, although it still obtains an efficacy of more than $50 \%$, not due to the response of the most innovative individuals, but to a late majority, or lagers. This evidence contradicts what the claims of recycling literature, namely that the individuals who are potentially most susceptible to respond to this technique are those who have a classically more innovative profile, in other words, those with greater cognitive and evaluative resources of an ecological and recycling nature (McKenzie-Mohr, 1999). The empirical evidence obtained in this work indicates that such efficacy is the result of an increase in the collaboration of individuals with a lower level of recycling behaviour, less knowledge of the how and why of recycling or recycling beliefs, and a less favourable attitude toward waste recycling. Therefore, from a practical point of view and in order to optimize the efficacy of this recycling promotion technique, it is necessary to consider a new target profile belonging to the so-called late majority, or the lagers.

In this mature phase of the recycling diffusion process, the response behaviour to the commitment at the incentive of a blockleader displays hardly any differences from the non-response behaviour. In fact, the existing differences are in minor details, not only from a longitudinal analysis, i.e. in the dynamics of the variables of processing or response, but also from a transversal analysis, i.e. in the structuring of the relationships between those variables and the resulting model of adoption through the effect of the technique. However, it is precisely those small differences that enable us to indicate implications for practical management. In the present state of diffusion, it is advisable to pay greater attention to the provision of information about the how and why of recycling, or recycling beliefs, as well as about the principal environmental problems and how to solve them, or ecological conscience. The beliefs about recycling and ecological concern are the contents that determine a greater recycling involvement and a more favourable attitude to recycling, respectively, at the same time as a stronger adoption process, that is, a greater internal consistency of cognitive and evaluative ecological and recycling resources. Therefore, the key to success for promoters of public policies, whose campaigns consist of using the commitment at the incentive of a blockleader technique, continues to lie in environmental education since the possibility of extending recycling behaviour depends on the acquisition of such knowledge. Hence the implementation of public campaigns to promote recycling should emphasize contents related to both social cost (in terms of non-recycling behaviour) and the benefit associated (in term of environmental welfare), conditioned to the recycling response collaboration performed.

Moreover, this work has shown that the perceived convenience of recycling does not significantly differ between non-responders and responders to the recycling promotion. As previously explained, this may be due to the fact that there are no substantial differences in their levels of cognitive and evaluative resources that determine the perception of the recycling situation. Only the perception of distance to the selective waste collection points, near to the critical threshold, seems to be more inconvenient for those who decide to increase their recycling collaboration as a result of the promotion. From a practical perspective, this finding leads us to recommend that a greater effort be made in the distribution of selective waste collection points since this is the main complaint of those who make a successful campaign possible. Furthermore, as Martínez et al. (1998) state, this loss of influence of the situational factors is consistent with the fact that, as the diffusion process becomes more advanced, the external factors lose importance in explaining adoption. Therefore, the major cost related to the recycling promotional method should neither be related to developing recycling collection infrastructure, nor on decreasing the household's time and effort to recycle. Once consumers have internalised the value of recycling, it will then possibly be the moment to implement sanctions against those opposed or reluctant. Additionally, we might think not only on taxing garbage presented by each household, but also on paying for any recycling material provided by the consumer. It is probable that we are approaching a new era where companies must compete to obtain recycling materials and as a result they should provide specific benefits, such as monetary remuneration or other perceived advantages or benefits, to the consumer/materials provider.

In light of these results, the analysis of reluctance to recycle is recommended as a future line of research. In fact, this work has clearly shown that non-response to the promotion should be understood as a delay of implementation. However, considering the sequential model of segments of adoption within the innovation diffusion process, it is to be expected that the early efficacy of the promotions depends more on the last segment of adopters. It is possible that the analysis of non-adoption by delayers responds to a pattern of reluctance with cognitive and evaluative antecedents opposed to recycling and what is ecological, and therefore nonadopters must be explained and managed differently from today's majority or favourable accepters. This future research hypothesis is based on a theoretical supposition defended by Ram (1987) regarding the linearity of the diffusion process, since it proposes the asymmetry of the innovation diffusion process when the potential adopter is opposed, displays negative motivation and holds feelings antithetic to the desired motivation and feelings. In this case, the non-adoption process should be considered a reluctance rather than an opposition to the notion of adoption in itself, and, in that respect, more attention should be paid to the deepest psychological principles rooted in the personality, such as reactance (Brehm, 1966; Snyder and Fromkin, 1980), the sense of non-conforming to the group (Strickland et al., 1970) and the materialistic tendency 
to consider personal beliefs and attitudes as exclusive personal belongings (Abelson and Prentice, 1989). In the end, as the adoption conduct advances in the diffusion process, it is the internal personal factors that exercise most influence (Martínez et al., 1998), with functional inhibitors, such as the pattern, the value, and the risk of assuming the adoption behaviour, losing importance, while aspects such as breaking with routine and the perception of social risk gain importance (Sheth, 1981).

\section{References}

Abelson, R., Prentice, D., 1989. Beliefs as possessions: a functional perspective. In: Pratkanis, A.R., Breckler, S.J., Greenwald, A.G. (Eds.), Attitude Structure and Function. Erlbaum, Hilldale, NJ, pp. 361-381.

Ackerman, F., 1997. Why Do We Recycle? Island Press, California.

Arcury, T., Johnson, T., Scollay, S., 1986. Ecological worlview and environmental knowledge: the new environmental paradigm. Journal of Environmental Education 17, 35-40.

Bagozzi, R., Dabholkar, P., 1994. Consumer recycling goals and their effect on decisions to recycle: a mean end chain analysis. Psychology and Marketing 11, 1-28.

Bigné, E., 1997. El consumidor verde: bases de un modelo de comportamiento [The green consumer: basis for a consumer behaviour model]. Esic-Market, 237-251.

Biswas, A., Licata, J., Mckee, D., Pullig, C., Daughtridge, C., 2000. The recycling cycle: an empirical examination of consumer waste recycling and recycling shopping behaviors. Journal of Public Policy and Marketing 19, 93-105.

Bohlen, G., Schlegelmilch, B., Diamantopoulos, A., 1993. Measuring ecological concern: a multi-construct perspective. Journal of Marketing Management 9, 415-430.

Brehm, J., 1966. A Theory of Psychological Reactance. Academic Press, New York.

Bryce, W., Day, R., Olney, T., 1997. Commitment approach to motivating community recycling: New Zealand curbside trial. The Journal of Consumers Affairs 31 (1), $27-53$

Burns, S., 1991. Social psychology and the stimulation of recycling behaviors: the blockleader approach. Journal of Applied Social Psychology 21 (8), 611-629.

Burns, S., Oskamp, S., 1986. Increasing community recycling with persuasive communication and public commitment. Journal of Applied Social Psychology 16 (1), 29-41.

Cacioppo, J., Petty, R., 1984. The elaboration likelihood model of persuasion. Advances in Consumer Research 11, 673-675.

Chaiken, S., Stangor, C., 1987. Attitudes and attitude change. Annual Review of Psychology 38, 575-630.

Diaz, G., Beerli, A., 2002. Cómo son las personas resistentes a reciclar: una aplicación empírica al reciclaje de vidrio [what people who are reluctant to recycle are really like]. In: Best Papers Proceedings 2002 XVI Congreso Nacional y XII Congreso Hispano Francés, Alicante.

Diaz, G., Beerli, A., Martin, J., 2004. El modelo de hábito de reciclado según el perfil sociodemográfico de los consumidores [The habit model of recycling according the sociodemographic profile of consumers]. XVI Encuentro de Profesores Universitarios de Marketing, 191-207.

Dietz, T., Stern, P., Guagnamo, G., 1998. Social structural and social psychological bases of environmental concern. Environment and Behavior 30, 450-471.

Dunlap, R., Van Liere, D., 1984. Commitment to the dominant social paradigm and concern for environmental quality. Social Science Quarterly 65 (4), 1013-1028.

Dwyer, W., Leeming, F., Cobern, M., Porter, B., Jackson, J., 1993. Critical review of behavioral interventions to preserve the environment: research since 1980. Environment and Behavior 25, 275-321.

Everett, J., Peirce, J., 1992. Social networks, socioeconomic status, and environmental collective action: residential curbside block leader recycling. Journal of Environmental Systems 21, 65-84.

Folz, D., 1991. Recycling program design, management and participation: a national survey of municipal experience. Public Administration Review 51 (3), 222-231.

Gamba, R., Oskamp, S., 1994. Factors influencing community residents participation in commingled curbside recycling programs. Environment and Behavior 26 (5), 587-612.

Gatignon, H., Robertson, T., 1989. Technology diffusion: an empirical test of competitive effects. Journal of Marketing 53 (1), 35-49.

Gerbing, D., Anderson, J., 1988. An updated paradigm for scale development incorporating unidimensionality and its assessment. Journal of Marketing Research 25, 186-192.

Grendstad, G., 1999. The new ecological paradigm scale: examination and scale analysis. Environmental Politics 8 (4), 194-205.

Grunert, S., Jorn, H., 1995. Values, environmental attitudes, and buying of organic foods. Journal of Consumer Marketing 16, 39-62.

Hair, J., Anderson, E., Tatham, R., Black, W., 1999. Análisis Multivariante, 5th ed Editorial Prentice Hall.

Hanson, J., 1980. A proposed paradigm for consumer product disposition processes. The Journal of Consumer Affairs 14 (1), 49-67.
Hirschman, E., 1987. Adoption of an incredibly complex innovation: propositions from a humanistic vantage point. In: Wallendorf, M., Anderson, P.F. (Eds.), Advances in Consumer Research, vol. 14. Association for Consumer Research, Provo, UT, pp. 57-60.

Hopper, J., Nielsen, J., 1991. Recycling as altruistic behavior. Normative and behavioral strategies to expand participation in a community recycling residence. Environment and Behavior 23 (2), 195-220.

Hornik, J., Cherian, J., Madansky, M., Narayana, C., 1995. Determinants of recycling behavior: a synthesis of research results. The Journal of Socio-Economics 24 (1), 105-127.

Howenstine, E., 1993. Market segmentation for recycling. Environment and Behavior 25 (1), 86-102.

Hoyer, W., Macinnis, D., 2004. Consumer Behavior. Houghhton Mifflin Company, Boston.

Katzev, R., Pardini, A., 1987. The comparative effectiveness of reward and commitment approaches in motivating community recycling. Journal of Environmental Systems 17, 93-113.

Martínez, E., Polo, Flavián, C., 1998. The acceptance and diffusion of new consumer durables: differences between first and last adopters. Journal of Consumer Marketing 15 (4), 323-342.

McGuiness, J., Jones, P., Cole, G., 1977. Attitudinal correlates of recycling behavior. Journal of Applied Psychology 62, 376-384.

McKenzie-Mohr, D., 1999. Fostering Sustainable Behavior. New Society Publisher.

Mittelstaedt, R., Grossbart, S., Curtis, W., Devere, S., 1976. Optimal stimulation level and the adoption decision process. Journal of Consumer Research 3, 84-94.

Moreno, R., López, J., 1985. Análisis metodológico de investigaciones experimentales en psicología [Methodological Analysis for Experimental Research in Psychology]. Editorial Alamex, S.A. Madrid.

Oskamp, S., Harrington, M., Edwards, T., Sherwood, D., Okuda, S., Swanson, D., 1991. Factors influencing household recycling behavior. Environment and Behavior 23 (4), 494-519.

Pardini, A., Katzev, R., 1983. The effect of strength of commitment on newspaper recycling. Journal of Environmental Systems 13, 245-254.

Petty, R., Krosnick, J., 1995. Attitude Strength: Antecedents and Consequences. Lawrence Erlbaum, Mahwah, NJ.

Porter, B., Leeming, F., Dwyer, W., 1995. Solid waste recovery. A review of behavioral programs to increase recycling. Environment and Behavior 27 (2), 122-152.

Ram, S., 1987. A model of innovation resistance. In: Walendorf, M., Anderson (Eds.), Advances in Consumer Research, vol. 14. Association for Consumer Research, Provo, UT.

Rogers, E.M., 1995. The Diffusion of Innovations, 3rd ed. The Free Press, New York.

Schlegelmilch, B., Bohlen, G., Diamantopoulos, A., 1996. The link between green purchasing decisions and measures of environmental consciousness. European Journal of Marketing 30 (5), 35-55

Sheth, J., 1981. Psychology of innovation resistance: the less developed concept (LDC) in diffusion research. Research in Marketing 4, 273-282.

Scholder, P., 1994. Do we know what we need to know? Objective and subjective knowledge effects on pro-ecological behaviors. Journal of Business Research 30, 43-52.

Schuhwerk, M., Lefkokk-Hagius, R., 1995. Green or non green? Does type of appeal matter when advertising a green product? Journal of Advertising 24, 45-55.

Shrum, L., Lowrey, T., 1995. Applying social and traditional marketing principles to the reduction of household waste. American Behavioral Scientist 38 (4), 646-658.

Snyder, C., Fromkin, H., 1980. Uniqueness: The Human Pursuit of Difference. Plenum Press, New York

Strickland, L., Messick, S., Jackson, D., 1970. Conformity, anticonformity and independence: their dimensionality and generality. Journal of Personality and Social Psychology 16, 497-507.

Venkatraman, M., 1991. The impact of innovativeness and innovation type of adoption. Journal of Retailing 67 (1), 51-68.

Vining, J., Ebreo, A., 1990. What makes a recycler? A comparison of recyclers and non recyclers. Environmental and Behavior 22 (1), 55-73.

Wang, T.Y., Katzev, R., 1990. Group commitment and resource conservation: two field experiments on promoting recycling. Journal of Applied Social Psychology 20, 265-275.

Wesley, P., Oskamp, S.Y., Mainieri, T., 1995. Who recycles and when? A review of personal and situational factors. Journal of Environmental Psychology 15, 105-121.

Williams, E., 1991. College students and recycling: their attitudes and behaviors. Journal of College Student Development 32, 86-88.

Young, R., 1988. Exploring the difference between recyclers and non recyclers: the role of information. Journal of Environmental Systems 18, 341-351.

Zaichkowsky, J., 1985. Measuring the involvement construct. Journal of Consumer Research 12, 341-352.

Zanna, M., Fazio, R., Ross, M., 1994. The persistence of persuasion. In: Shank y, R.C., Langer, E. (Eds.), Beliefs, Reasoning, and Decision Making: Psychologic in Honor of Bob Abelson. Lawrence Erlbaum, Hillsdale, NJ, pp. 347-362.

Zimmer, M., Stafford, T., Royne, M., 1994. Green issues: dimensions of environmental concern. Journal of Business Research 30, 63-74. 